ISSN 2313-7347 (print) ISSN 2500-3194 (online)

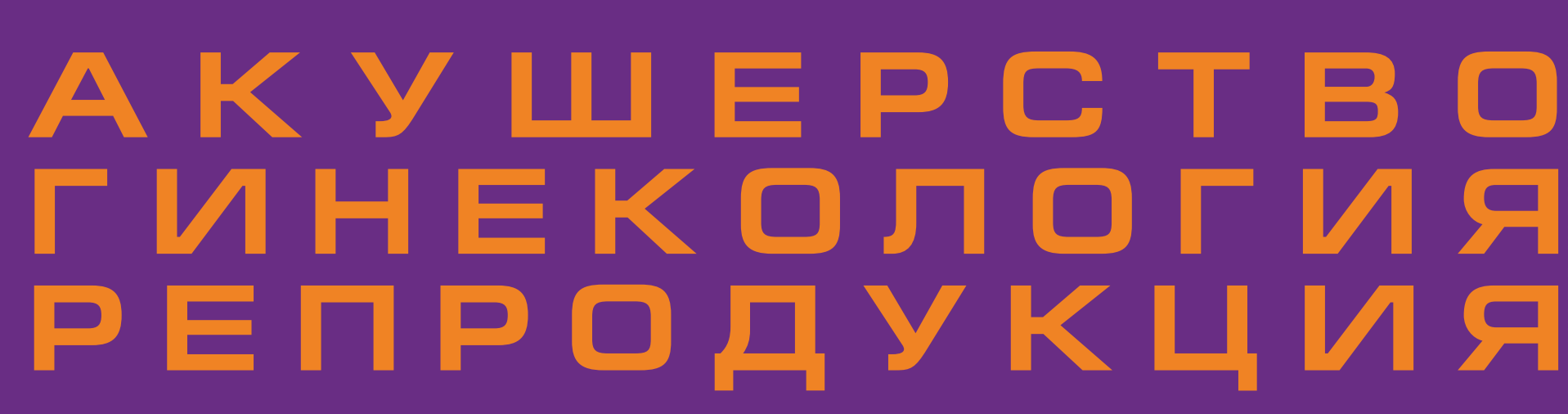

Включен в перечень ведущих рецензируемых журналов и изданий ВАК

$2020 \bullet$ том $14 \cdot$ № 3

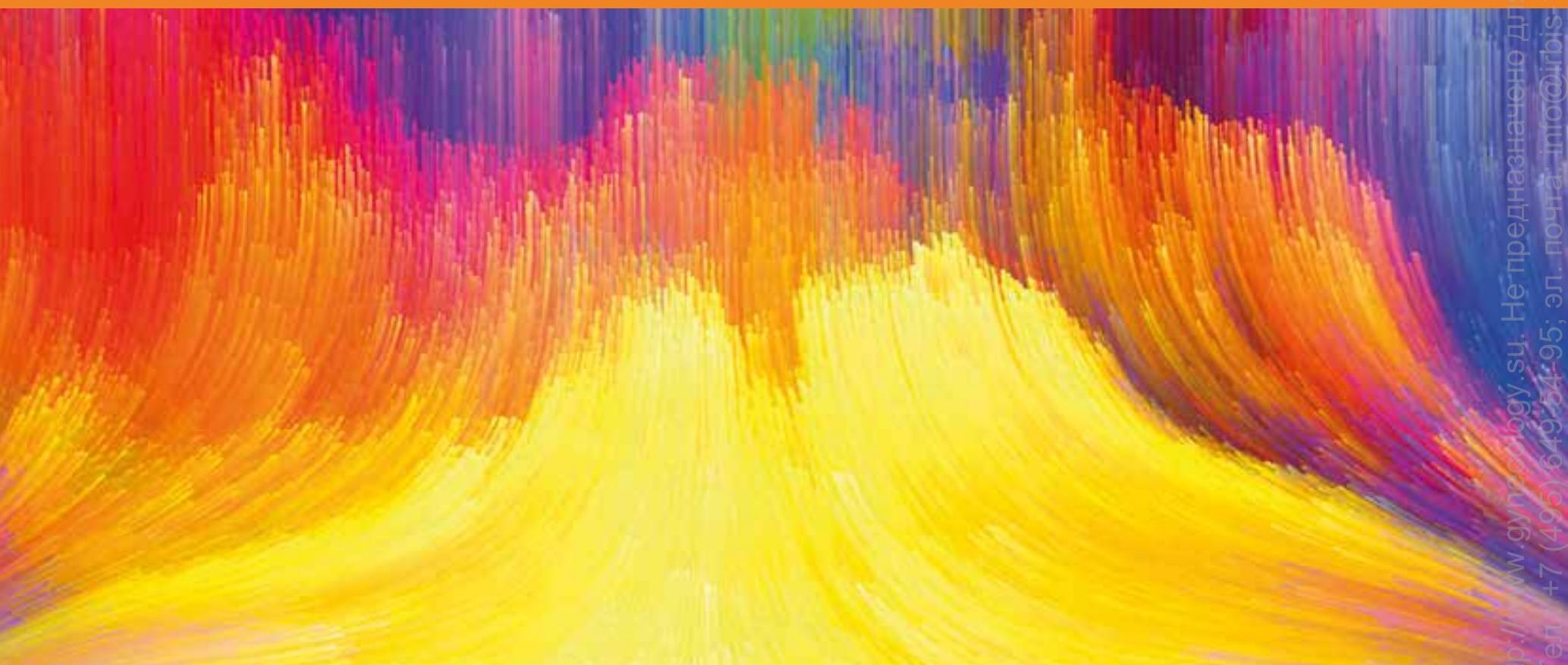




\title{
Септический шок
}

\author{
В.О. Бицадзе ${ }^{1}$, Т.А. Суконцева², С.В. Акиньшина', Я.Ю. Сулина', \\ Д.Х. Хизроева ${ }^{1}$, М.В. Третьякова ${ }^{3}$, Х.Г. Султангаджиева ${ }^{1}$, Д.Ю. Унгиадзе ${ }^{4,5}$, \\ Н.В. Самбурова ${ }^{1}$, К.Н. Григорьева ${ }^{1}$, В.И. Цибизова ${ }^{6}$, А.С. Шкода7, \\ Д.В. Блинов ${ }^{8,9,10}$, А.Д. Макацария ${ }^{1}$
}

\author{
${ }^{1}$ ФГАОУ ВО Первый Московский государственный медицинский университет \\ имени И.М. Сеченова Министерства здравоохранения Российской Федерации (Сеченовский Университет); \\ Россия, 109004 Москва, ул. Земляной Вал, д. 62;
}

\begin{abstract}
${ }^{2}$ ФГБОУ ВО «Первый Санкт-Петербургский государственный медицинский университет имени академика И.П. Павлова» Министерства здравоохранения Российской Федерации; Россия, 197022 Санкт-Петербург, ул. Льва Толстого, д. 6/8;

${ }^{3} 000$ «Лечебный Центр», Россия, 119021 Москва, ул. Тимура Фрунзе, д. 15/1;
\end{abstract}

${ }^{4}$ Батумский государственный университет имени Шота Руставели; Грузия, 6010 Батуми, ул. Ниношвили, д. 35;

${ }^{5} Ц$ ентр здоровья «Медина» имени Ирис Борчашвили; Грузия, 6004 Батуми, проспект Фридон Халваши, д. 237;

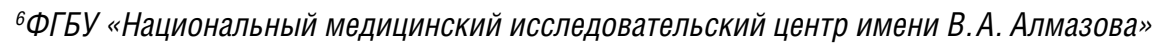
Министерства здравоохранения Российской Федерации;

Россия, 197341 Санкт-Петербург, ул. Аккуратова, д. 2;

7ГБУЗ «Городская клиническая больница № 67 имени Л.А. Ворохобова

Департамента здравоохранения города Москвы»;

Россия, 123423 Москва, ул. Саляма Адиля, д. 2/44;

${ }^{8}$ Институт Превентивной и Социальной Медицины;

Россия, 127006 Москва, ул. Садовая-Триумфальная, д. 4-10;

${ }^{9}$ Клинический Госпиталь Лапино, ГК «Мать и Дитя»;

Россия, 143081 Московская область, Одинцовский район, Лапино, 1-е Успенское шоссе, д. 111;
${ }^{10}$ Автономная некоммерческая организация дополнительного профессионального образования «Московский медико-социальный институт имени Ф.П. Гааза»;
Россия, 123056 Москва, 2-я Брестская улица, д. 5, стр. 1-1а

Для контактов: Александр Давидович Макацария, e-mail: gemostasis@mail.ru

\section{Резюме}

Проблема сепсиса и септического шока в последнее время становится все более актуальной. В акушерстве и гинекологии количество случаев сепсиса за последние 10 лет выросло более чем в 2 раза. В обзоре рассматриваются клинические формы септических состояний, фракторы риска, патогенез сепсиса и септического шока, основные возбудители септических состояний. Особое внимание уделено неонатальному сепсису. Связь септического шока с вирусными инфекциями рассмотрена в призме пандемии новой коронавирусной инфекции (COVID-19), вызываемой SARS-CoV-2. Продемонстрированы нарушения гемостаза у больных септическим шоком, включая синдром диссеминированного внутрисосудистого свертывания (ДВС-синдром). Обсуждается значимость определения уровня ADAMTS-13 для уточнения прогноза.

Ключевые слова: сепсис, септический шок, патогенез, ДВС-синдром, ADAMTS-13

Для цитирования: Бицадзе В. О., Суконцева Т.А., Акиньшина С.В., Сулина Я. Ю., Хизроева Д.Х., Третьякова М.В., Султангаджиева Х.Г., Унгиадзе Д.Ю., Самбурова Н.В., Григорьева К. Н., Цибизова В.И., Шкода А.С., Блинов Д.В., Макацария А.Д. Септический шок. Акушерство, Гинекология и Репродукция. 2020;14(3):314-326. https://doi.org/10.17749/2313-7347/ob.gyn.rep.2020.169. 


\section{Septic shock}

\section{Viktoria O. Bitsadze', Tatyana A. Sukontseva², Svetlana V. Akinshina', Yana Yu. Sulina', Jamilya Kh. Khizroeva' ${ }^{1}$, Maria V. Tretyakova ${ }^{3}$, Khadizhat G. Sultangadzhieva' ${ }^{1}$ Jumber Yu. Ungiadze ${ }^{4,5}$, Natalia V. Samburova ${ }^{1}$, Kristina N. Grigoreva ${ }^{1}$, Valentina I. Tsibizova ${ }^{6}$, Andrey S. Shkoda ${ }^{7}$, Dmitry V. Blinov ${ }^{8,9,10}$, Alexander D. Makatsariya ${ }^{1}$}

${ }^{1}$ Sechenov University; 62 Str. Zemlyanoi Val, Moscow 109004, Russia;

2.P. Pavlov First Saint Petersburg State Medical University, Health Ministry of Russian Federation; 6/8 Lev Tolstoy Str., Saint Petersburg 197022, Russia;

${ }_{3}$ «Medical Center» LLC; 15/1 Timura Frunze Str., Moscow 119021, Russia;

${ }^{4}$ Shota Rustaveli Batumi State University; 35 Ninoshvili Str., Batumi, 6010, Georgia;

5/ris Borchashvili Health Center Medina; 237 Fridon Khalvashi Avenue, Batumi6004, Georgia;

${ }^{6}$ Almazov National Medical Research Centre, Health Ministry of Russian Federation; 2 Akkuratova Str., Saint Petersburg 197341, Russia;

${ }^{7}$ City Clinical Hospital № 67 named after L.A. Vorokhobov, Moscow Healthcare Department; 2/44 Salyama Adilya Str., Moscow 123423, Russia;

8Institute for Preventive and Social Medicine; 4-10 Sadovaya-Triumfalnaya Str., Moscow 127006, Russia;

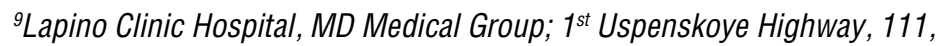
Moscow Region, Odintsovo District, Lapino 143081, Russia;

${ }^{10}$ Moscow Haass Medical - Social Institute; 5, 1-1a 2nd Brestskaya Str., Moscow 123056, Russia

Corresponding author: Alexander D. Makatsariya, e-mail: gemostasis@mail.ru

\section{Abstract}

Recently, it has been increasingly apparent that sepsis and septic shock become a pressing issue. Over the last decade, incidence rate of sepsis in obstetrics and gynecology has been increased by more than 2-fold. Here we review clinical forms of septic conditions, risk factors, pathogenesis of sepsis and septic shock, as well as major pathogens resulting in septic conditions. Special attention is paid to neonatal sepsis. The relationship between septic shock and viral infections is considered in the context of the novel coronavirus infection (COVID-19) pandemic caused by SARS-CoV-2. Impaired hemostasis is discussed in patients with septic shock, including those with disseminated intravascular coagulation (DIC). An importance of assessing ADAMTS-13 level to refine disease prognosis is discussed.

Keywords: sepsis, septic shock, pathogenesis, disseminated intravascular coagulation, DIC, ADAMTS-13

For citation: Bitsadze V. O., Sukontseva T. A., Akinshina S. V., Sulina Ya. Yu., Khizroeva J. Kh., Tretyakova M. V., Sultangadzhieva Kh. G., Ungiadze J. Yu., Samburova N. V., Grigorieva K. N., Tsibizova V. I., Shkoda A. S., Blinov D. V., Makatsariya A. D. Septic shock. Akusherstvo, Ginekologia $i$ Reprodukcia = Obstetrics, Gynecology and Reproduction. 2020;14(3)314-326. (In Russ.). https://doi.org/10.17749/2313-7347/ob.gyn.rep.2020.169.

\section{Введение / Introduction}

Сепсис и септический шок представляют собой обширную и крайне актуальную проблему современной медицины. Они являются результатом дисрегуляции ответа организма хозяина на инфекцию с последующим поражением любых систем органов. За последние 10 лет наблюдается значительное увеличение числа больных сепсисом, что связывают с ростом количества пациентов с иммунодесицитным статусом [1]. По данным исследований из Новой Зеландии и Австралии, внутрибольничная смертность от сепсиса среди молодых людей (менее 44 лет, средний возраст - 31,2 года) составляет $12 \%$, при отсутствии сопутствующих заболеваний - $8 \%$. Однако количество внутрибольничных случаев смерти пациентов, страда- ющих сепсисом, имеет тенденцию к снижению. Так, согласно данным некоторых исследований, оно снизилось с 39,6 \% в 2001 г. до 27,3 \% в 2007 г. [2-4].

В акушерстве и гинекологии на долю материнских смертей от септических осложнений приходится от 4 до 10 случаев на 10 тыс. живых новорожденных. Согласно данным коллег из США, количество случаев ассоциированного с беременностью сепсиса возросло с 11 на 10 тыс. в 2001 г. до 26 на 10 тыс. в 2010 г. [2].

Вопросы септических осложнений крайне важны для акушеров-гинекологов и врачей других профилей не только из-за высокого риска летального исхода, но также из-за возможности развития осложнений, в том числе ухудшения качества жизни пациента в дальнейшем. 


\section{Определение и факторы риска /}

\section{Definition and risk factors}

Выделяют следующие клинические формы септических состояний.

1. Синдром системного воспалительного ответа (ССBO, англ. systemic inflammatory response syndrome, SIRS) представляет собой системную реакцию организма на влияющий на него повреждающий стресс, в роли которого могут выступать инфекция, травма, оперативное вмешательство и др. Диагностическими критериями являются температура тела $\geq 38{ }^{\circ} \mathrm{C}$ или $\leq 36{ }^{\circ} \mathrm{C}$, частота сердечных сокращений $\geq 90$ уд/мин, частота дыхания $\geq 20$ в минуту или гипервентиляция с содержанием диоксида углерода в крови $\leq 32$ мм рт. ст., лейкоцитоз $\geq 12 \times 10 \% / л$ или лейкопения $\leq 4 \times 10 \%$ л.

2. Сепсис - это ССВО при признаках инфекции (подозреваемая или документированная инфекция). Согласно данным III Международного консенсуса по определению сепсиса, это «угрожающая жизни органная дисфрункция, вызванная дисрегуляцией ответа организма хозяина на инфекцию» [2].

3. Тяжелый сепсис - сепсис, сопровождающийся нарушением работы сердечно-сосудистой системы и/или острым респираторным дистресс-синдромом и/или нарушением функции двух и более других систем органов.

4. Септический шок представляет собой тяжелый сепсис с признаками нарушения работы сердечно-сосудистой системы.

5. Синдром полиорганной недостаточности (ПОН).

Основными аспектами патогенеза событий при системном воспалении являются первичная и вторичная системная альтерация, неадекватность противовоспалительного ответа, расстройства микроциркуляции с дальнейшим развитием ПОН и системная тканевая деструкция [5].

Септический шок был определен M. Singer c соавт. как клинический вариант сепсиса, при котором глубокие циркуляторные и клеточные/метаболические нарушения достаточны для значительного увеличения смертности. Кроме того, среди различных используемых определений часто встречается вариант описания септического шока в концепции сепсиса с персистирующей гипотензией, требующей вазопрессорной терапии для поддержания уровня артериального давления (АД) $\geq 65$ мм рт. ст., а также уровня лактата $\geq 2$ ммоль/л при адекватной инфузионной терапии, что в целом повышает риск летального исхода [6]. Главной отличительной чертой септического шока является высокая степень выраженности ПОН, в основе которой лежит расстройство микроциркуляции.

Степень дисфункции органов объективно определяется по шкале SOFA (англ. Sequential Organ Failure Assessment) и quick SOFA (qSOFA), внедренной в клиническую практику. В qSOFA используется 3 критерия: систолическое АД < 100 мм рт. ст., частота дыхания $\geq 22$ в минуту и изменение психического статуса. Два и более положительных критерия говорят о повышении риска неблагоприятных исходов сепсиса. Значение в 2 балла говорит об увеличении риска летального исхода как минимум на 10 \% в сравнении с индексом в 1 балл [7].

Среди фракторов риска развития сепсиса выделяют возраст старше 35 лет, диабет, артериальную гипертензию, негроидную или азиатскую расовую принадлежность, латиноамериканское происхождение, курение, а также отсутствие медицинской страховки и высшего или среднего образования у пациента, что говорит о большой значимости социального фактора в развитии септических осложнений [8]. Также к ним относятся первые роды, множественные беременности, многоплодная беременность, родоразрешение путем кесарева сечения и использование вспомогательных репродуктивных технологий. Осложнения нормального течения беременности, такие как преэклампсия и эклампсия, в 3 раза чаще встречались у пациенток с септическим шоком по сравнению с пациентками с тяжелым сепсисом [9].

Безусловно, отягощенный преморбидный фон значительно утяжеляет течение сепсиса, например, у пациентов с ВИЧ, хронической сердечной, печеночной или почечной недостаточностью, системной красной волчанкой и другими аутоиммунными заболеваниями [8].

Такие осложнения, как хориоамнионит и послеродовые инфекции сами по себе ассоциированы с развитием сепсиса, так как представляют собой непосредственный источник распространения микроорганизма в ослабленном родами организме женщины. Однако, согласно исследованиям, пациентки с хориоамнионитом реже погибают от сепсиса, что связывают с его лучшим диагностированием и ранним началом терапии [10]. Такая статистика еще раз доказывает необходимость оптимизации диагностического процесса и раннего начала терапии при септических осложнениях с целью значительного снижения смертности пациентов.

\section{Патогенез сепсиса и септического шока / Pathogenesis of sepsis and septic shock}

Взаимодействие макро- и микроорганизма представляет собой сложную систему последовательных реакций и событий, в результате которых запускаются как иммунологические, так и неиммунологические звенья патогенеза, а именно нейрональное, сердечно-сосудистое, гормональное, биоэнергетическое, метаболическое и коагуляционное звено [11, 12]. Сила, с которой организм хозяина разовьет этот ответ, зависит от множества фракторов, таких как пол, возраст, расовая принадлежность, коморбидность, а также осуществленные медицинские вмешательства, выступающие в роли стрессового фактора. 
Важная роль в развитии сепсиса и септического шока принадлежит системе комплемента. В результате каскада реакций, ведущих к образованию мембраноатакующего комплекса (МАK), компоненты СЗа и С5а начинают выступать в роли мощных хемоаттрактантов, привлекая нейтрофилы и макрофаги. Происходит значительный выброс цитокинов, таких как интерлейкин-8 (IL-8), фрактор некроза опухоли-альсра (англ. tumor necrosis factor- $\alpha$, TNF- $\alpha$ ), а также гистамина. Полагается, что «сбой» именно на данном этапе и выступает в качестве пускового механизма в развитии сепсиса. Высвобождение крупного пула цитокинов приводит к повреждению эндотелия сосудов с повышением его проницаемости за счет адгезии нейтрофилов. Выход жидкости в межклеточное пространство сопровождается нарушением микроциркуляции и отеком. Кроме того, из поврежденных эндотелиоцитов в значительном количестве выделяется оксид азота, что ведет сначала к вазодилатации и гипотонии, а затем и к вазоплегии. У более чем $60 \%$ пациентов с сепсисом фрракция выброса составляет менее $45 \%$ это систолическая дисфуннция. Также дебютом септической кардиомиопатии может быть и диастолическая диссрункция за счет кардиогенных отеков [2].

В условиях децентрализации кровотока развивается гипоксия и ишемия тканей и органов. Аэробный гликолиз сменяется на анаэробный, в результате чего происходит накопление активных форм кислорода, которое запускает перекисное окисление липидов, что в свою очередь активирует систему комплемента по лектиновому пути [13]. Стоит отметить, что ишемия органов при сепсисе и септическом шоке носит не только циркуляторный характер, но также может быть следствием микротромбозов при развитии ДВС-синдрома.

\section{Микробиология септического шока / Microbiology of septic shock}

Для развития такого состояния, как септический шок, необходимым условием является присутствие микроорганизма, способного к инвазии, в сочетании с нарушением функционирования иммунной системы организма [14]. К сожалению, в 30 \% случаев источник инфекции найти не удается, а в $16 \%$ не удается обнаружить ни возбудителя, ни источник [15].

В акушерстве и гинекологии основными возбудителями септических состояний у пациенток являются следующие микроорганизмы: грамотрицательные бактерии Escherichia coli, Klebsiella sp., Proteus sp., Hemophilus influenzae, Enterobacter sp., Pseudomonas sp., Serratia sp.; грамположительные бактерии Pneumococcus, Streptococcus групп A, B и D, Staphylococcus aureus, Listeria monocytogenes, Enterococcus; анаэробные бактерии Bacteroides sp., Peptococcus, Clostridium perfringens, Fusobacterium sp., Peptostreptococcus [15-18]. Возможно развитие полимикробной инфекции [19].
В последних рекомендациях по ведению пациентов с сепсисом и септическим шоком настойчиво рекомендуется начинать эмпирическую терапию антибиотиками широкого спектра действия до обнаружения конкретного возбудителя, чем скорее, тем лучше, в идеале - в течение 1 часа после установки диагноза, особенно у беременных с подозрением на сепсис [2, 14]. В дальнейшем, после обнаружения культуры возбудителя, терапия должна быть скорректирована согласно чувствительности микроорганизма.

\section{Неонатальный сепсис / Neonatal Sepsis}

Большой проблемой современной медицины и перинатологии остается сепсис новорожденных. Выделяют ранний и поздний неонатальный сепсис. Ранний (или врожденный) этиологически связан с анте- и интранатальным инфицированием. Симптомы в таком случае появляются уже в первые трое суток с момента рождения. Поздний, в свою очередь, связан с постнатальной инфекцией, и его клинические проявления возникают на 4-й день жизни и позднее.

Проявления неонатального сепсиса неспецифичны. Они включают лихорадку или гипотермию, респираторный дистресс-синдром, включая цианоз, апноэ, также трудности с кормлением, вялость, судороги, выбухание родничка, плохую перфузия тканей и т. д. Такое разнообразие и малая специфичность симптомов объясняют трудности диагностики данного состояния у новорожденных [20].

Имеется обратная зависимость более высокого риска неонатального сепсиса от степени доношенности ребенка, что обусловлено незавершенностью процессов формирования иммунной системы у глубоко недоношенных детей. Кроме того, такие дети обычно нуждаются в длительной респираторной поддержке, инвазивных вмешательствах, в том числе постановке центральных сосудистых катетеров, которые выступают в качества фрактора риска развития как септических, так и тромботических осложнений [21].

«Золотым стандартом» в диагностике сепсиса является выделение гемокультур, так как остальные методы (клиническая картина, критерии синдрома системного воспалительного ответа и др.) не являются достаточно специфичными. Но и данный метод имеет свои недостатки, так как минимальный необходимый объем крови (0,5 мл) для недоношенного ребенка с массой тела около 1 кг составляет примерно $10 \%$ объема всей циркулирующей крови, что делает невозможным одномоментный забор необходимого объема [22-24]. Важно, что отсутствие положительного ответа гемокультур не исключает наличие сепсиса.

Сегодня существуют методы, позволяющие оценивать биологические маркеры сепсиса, наиболее перспективным из которых является прокальцитонин. Однако он скорее применяется для решения вопроса об отмене нерациональной антибиотикотерапии 
у новорожденных с подозрением на сепсис, нежели для диагностики.

\section{Септический шок и вирусные} инфекции / Septic shock and viral infections

Для развития такого состояния, как септический шок, необходимым условием является присутствие агента, способного к инвазии, в сочетании с нарушением функционирования иммунной системы организма [14]. Проблема септического шока привлекла к себе высокое внимание в призме пандемии новой коронавирусной инфекции (COVID-19), вызываемой SARS-CoV-2 [25].

Взаимодействие макро- и микроорганизма представляет собой сложную систему последовательных реакций и событий, в результате которых запускаются как иммунологические, так и неиммунологические звенья патогенеза, а именно нейрональное, сердечно-сосудистое, гормональное, биоэнергетическое, метаболическое и коагуляционное звено [11, 12]. Сила, с которой организм хозяина разовьет этот ответ, зависит от множества факторов, таких как пол, возраст, расовая принадлежность, коморбидность, а также осуществленные медицинские вмешательства, выступающие в роли стрессового фактора. Хотя исследования продолжаются, уже сегодня продемонстрировано, что повышенное тромбообразование преимущественно в микрокапиллярном русле с развитием коагулопатии, ДВС-синдрома и септического шока является одним из ведущих механизмов в патогенезе COVID-19 [26-29].

Поэтому наряду с эмпирической терапией (гидроксихлорохин, антибиотики широкого спектра действия, противовирусные препараты лопинавир/ритонавир или дарунавир), иммунной терапией реконвалесцентной плазмой и средствами блокады ангиотензинпревращающего фермента 2-го типа (АПФ-2) применяется терапия, направленная на торможение цитокинового и тромботического шторма, коагулопатии и ДВСсиндрома. В частности, профилактическую дозу низкомолекулярных гепаринов (НМГ) - эноксапарин натрия и проч. следует назначать всем требующим госпитализации пациентам, включая некритических больных [26-29].

\section{Септические состояния и гемостаз / Septic states and hemostasis}

У больных септическим шоком превалируют выраженные нарушения гемостаза, которые могут протекать в хронической, подострой и острой форме (ДВС-синдром).

Связь воспаления и гемостаза рассматривается с позиции «петли усиления» - воспаление запускает и поддерживает процессы коагуляции, а продукты коагуляции поддерживают и усиливают воспаление.
Нарушаются не только те механизмы, которые угнетают фрибринолиз и способствуют коагуляции, но также и естественные антикоагулянтные системы, такие как антитромбин, система протеина С и ингибитор тканевого фрактора [30].

Активация гемостаза при сепсисе и септическом шоке происходит при повреждении эндотелия сосудов токсинами патогенного микроорганизма, активированными иммунокомпетентными клетками крови, провоспалительными цитокинами с продукцией и высвобождением тканевого фрактора (ТФ), главным образом моноцитами-макрофагами и эндотелиальными клетками [28, 31, 32]. Немалое значение играет и фрактор активации тромбоцитов (ФАТ). Другой механизм осуществляется за счет Р-селектина на мембране активированных тромбоцитов, который не только обеспечивает адгезию их к лейкоцитам и эндотелиоцитам сосудов, но также усиливает выработку ТФ моноцитами [33]. При системном воспалении уровень Р-селектина достоверно повышается.

Одной из особенностей является то, что сепсис ведет к повышенному высвобождению ингибитора активатора плазминогена 1-го типа (англ. plasminogen activator inhibitor type 1, PAl-1) из эндотелиоцитов, который угнетает активность плазмина. Бактериемия ассоциирована с ранней активацией фибринолиза за счет повышения уровня тканевого активатора плазминогена (англ. tissue-type plasminogen activator, tPA), что ведет за собой ответное высвобождение PAI-1. Фибринолиз подавляется. Но повышению уровня PAI-1 способствует не только появление tPA, но и ряд цитокинов (например, TNF- $\alpha$, IL-6 и др.). Следует отметить, что повышение уровей TNF- $\alpha$ и PAI-1 у пациентов напрямую коррелирует с тяжестью течения ДВС и сепсиса, а также достоверно ассоциировано с неблагоприятным прогнозом и высоким риском летального исхода.

Еще одним немаловажным аспектом в нарушении системы гемостаза является тромбин-активируемый ингибитор ффибринолиза (англ. thrombin-activatable fibrinolysis inhibitor, TAFI) [34-36]. Активированный TAFI подавляет фрибринолиз посредством удаления концевой молекулы лизина в фибрине, ингибируя тем самым высокоафффинный сайт для связывания с плазмином [37].

Что касается роли СКК, то компонент С5а активирует пристеночную систему коагуляции, а именно, фактор XII и калликреин, что сопровождается макротромбозами и развитием ДВС-синдрома.

При сепсисе и септическом шоке адекватная регуляция организма становится невозможна, в результате чего происходит его повреждение (рис. 1). Так, например, тромбин начинает поддерживать воспаление, поскольку он способен самостоятельно индуцировать воспалительный ответ эндотелия, активировать лейкоциты с привлечением их к эндотелиоцитам и дальней их адгезией. Клеточные эфффекты тромбина 


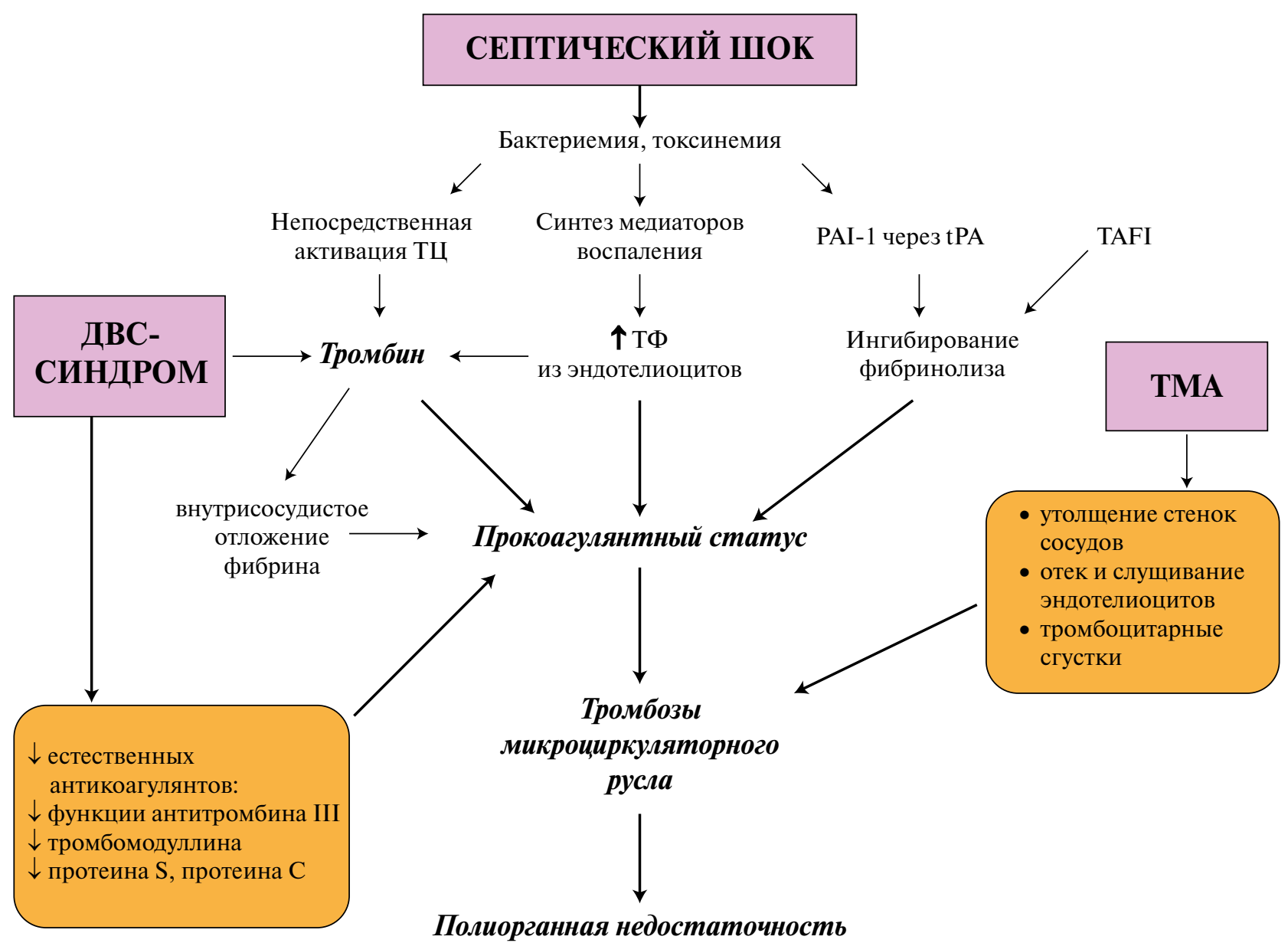

Рисунок 1. Патогенез развития полиорганной недостаточности при септическом шоке.

Figure 1. Pathogenesis of multiple organ failure in septic shock.

заключаются в активации эндотелиальных рецепторов PAR-1 (англ. protease-activated receptor 1), которые способны инициировать ответ клетки в регуляции провоспалительной реакции [38, 39]. Ряд авторов рассматривают ингибирование тромбина посредством применения антитромбина перспективным направлением в терапии септического шока и сепсиса $[40,41]$.

ПОН при септическом шоке возникает в результате тромбоза сосудов микроциркуляторного русла. Этому способствует общее прокоагулянтное состояние системы гемостаза в организме больного. Микроорганизмы и их токсины могут как непосредственно активировать тромбоциты, приводя к повышенной генерации тромбина, так и опосредованно, за счет повреждения эндотелиоцитов и стимуляции синтеза провоспалительных цитокинов с последующим высвобождением ТФ. Воспалительный ответ приводит к повышенной выработке tPA, что приводит к ответному высвобождению его ингибитора (PAl-1) и прекращению фибринолиза. Этому также способствует генерация тромбин-активируемого ингибитора фрибринолиза (TAFI). K повышенному образованию тромбина приводит также развивающийся на фоне септического шока
ДВС-синдром. На его фоне также происходит снижение активности естественных антикоагулянтных систем. В результате в сосудах идет активное отложение фрибрина, что ведет к дальнейшим тромбозам [42]. Крайне неблагоприятным считается развитие септического шока у пациентов с уже имеющейся тромботической микроангиопатией (TMA), на фоне которой имеет место утолщение сосудистой стенки, отек и слущивание эндотелиоцитов, а также образование тромбоцитарных сгустков [43].

Кроме проявлений ДВС-синдрома, пациенты с сепсисом и септическим шоком могут демонстрировать признаки тромботической тромбоцитопенической пурпуры (ТТП) - патологии, возникающей в результате врожденного или чаще приобретенного десрицита металлопротеиназы ADAMTS-13 (англ. A Disintegrin and Metalloproteinase with Thrombospondin type 1 motif, member 13), основной ролью которой является расщепление фактора фон Виллебранда (von Willebrand factor, vWF) на мономерные фррагменты (рис. 2). Такой десицит ведет к микроваскулярной обструкции с повреждением органов, в значительной степени головного мозга и почек, а также тромбоцитопении 


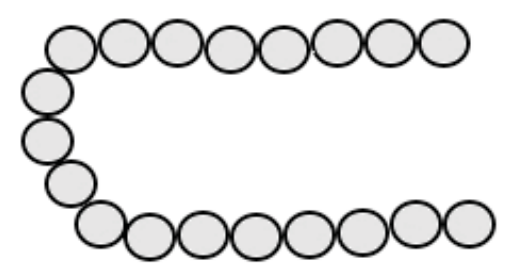

Мультимер

vWF

(активный)

ADAMTS-13
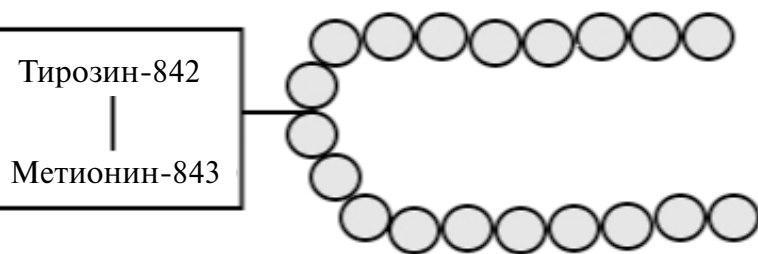

ADAMTS-13
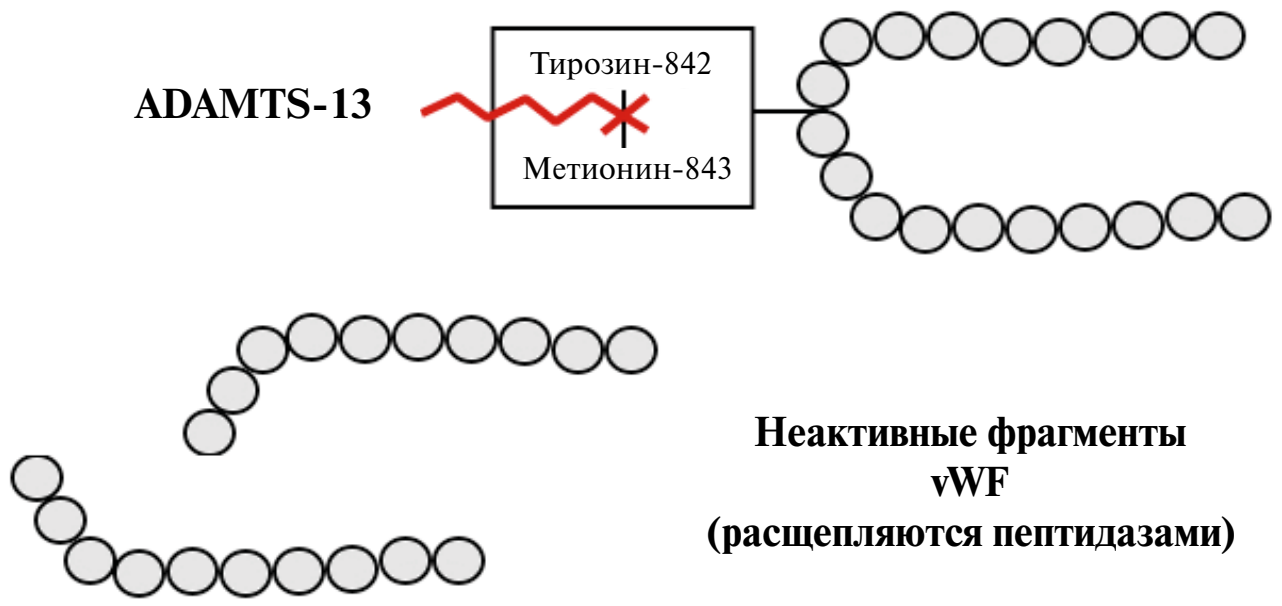

\author{
Неактивные фрагменты \\ vWF
}

(расщепляются пептидазами)

Рисунок 2. Биологическая роль ADAMTS-13.

Figure 2. Biological role of ADAMTS-13.

и неимунной гемолитической анемии [44]. Кроме чрезмерного потребления, тромбоцитопения (число тромбоцитов менее $100 \times 10^{9} /$ л) у пациентов с сепсисом может быть обусловлена замедленным их образованием или секвестрацией в селезенке [45].

Во время системного воспаления VWF значительно повышается за счет реакции эндотелиоцитов (примерно в 11 раз по сравнению с контрольной группой), что в итоге приводит к усилению взаимодействия тромбоцит-сосудистая стенка $[46,47]$. Считается, что уровень мультимеров VWF в крови пациентов, страдающих от сепсиса, прямо коррелирует с тяжестью течения заболевания [48]. Кроме роли связующего звена между тромбоцитами и сосудистой стенкой, VWF также является аттрактантом для лейкоцитов, содействует активации системы комплемента, о роли которой было упомянуто ранее, а также облегчает адгезию патогенных микроорганизмов к эндотелию [49].

Согласно данным ряда исследований, более трети пациентов с сепсисом имеют уровень ADAMTS-13 менее $50 \%$ от нормального значения, а около $15 \%$ пациентов - менее 10 \% от нормы. Чем ниже уровень ADAMTS-13, тем выше риск летального исхода у пациентов с сепсисом и септическим шоком [7, 46, 50, 51], так как десицит фрермента ведет к накоплению и увеличению продолжительности действия VWF, что ассоциировано с увеличением смертности пациентов за счет формирования протромботического статуса $[52,53]$.

ТТП как возможная патология должна быть рассмотрена врачами различных специализаций при выявлении типичных клинических признаков. Например, при обнаружении у беременной или родильницы микроангиопатической гемолитической анемии и тромбоцитопении необходимо заподозрить преэклампсию с тяжелым течением, гемолизом, повышением уровня печеночных ферментов и низкими тромбоцитами, комплемент-опосредованную тромботическую микроангиопатию и ТТП [54]. Кроме того, похожие клинические проявления могут возникать у пациентов с онкологическими заболеваниями, например, метастазирующим раком предстательной железы у мужчин (необходимо исследование уровня ADAMTS-13 для решения вопроса о дальнейшем поиске патологии, так как у таких пациентов он чаще нормальный) [55].

В развитии ТТП в качестве триггерного фрактора может выступать прием некоторых лекарственных препаратов. Например, Митомицин C (противоопухолевый алкилирующий агент, применяемый при онкологическом поражении молочной железы, желудка, 
легких, поджелудочной железы и др.) сам по себе не вызывает развитие ТТП, однако при биопсии почки у пациентов, находящихся на терапии Митомицином C, обнаруживают идентичные изменения почечной паренхимы, как и при ТТП. Циклоспорин, используемый при ряде аутоиммунных заболеваний, таких как ревматоидный артрит, а также при трансплантации органов и тканей для создания иммуносупрессии, имеет достаточно выраженную нефротоксичность, одним из проявлений которой может быть острое повреждение почек по типу такового при ТТП. Индуцировать ТТП могут также такие препараты, как хинин, тиклопидин (однако, согласно некоторым исследованиям, он успешно применяется для предотвращения рецидивов данного заболевания [56]), клопидогрел $[57,58]$. Около 75 лекарственных препаратов описаны рядом исследователей как потенциально ассоциированные с развитием ТТП: 51 из них за счет иммунного механизма, 26 за счет токсического, 2 (гемцитабин и оксалиплатин) за счет смешанного механизма [59].

Крайне неблагоприятно сочетание септического шока с циркуляцией в крови антифоссролипидных антител (аФЛ-АТ). Может также иметь место развитие катастрофического антифоссролипидного синдрома (КАФС), который представляет собой наиболее тяжелую форму антифоссфолипидного синдрома с развитием тромбозов жизненно важных органов и развитием ПОН [60]. Учитывая вышесказанное, клиническая картина ПОН при септическом шоке и КАФС может быть идентичной, что сильно затрудняет дифференциальнуюдиагностику. Согласно мнению R. A. Asherson c соавт., протекание септического шока на фоне циркуляции аФЛ-АТ может иметь неблагоприятные отдаленные последствия, обусловленные тромбозами надпочечников, гипофиза и других органов, с развитием в будущем у таких пациентов состояний, подобных синдрому Уотерхауса-Фридериксена, синдрому Шихана и т. д. Риск подобных осложнений тем выше, чем дольше пациент находится в критическом состоянии. Данное утверждение одинаково характерно для пациентов взрослого возраста, а также для неонатального периода [61-63].

\section{Заключение / Conclusion}

Септические состояния были, есть и будут одной из актуальнейших проблем здравоохранения. Высокая летальность, множественные осложнения и, следовательно, ухудшение качества жизни пациентов, подверженность различных возрастных категорий, а также значительные затраты на фринансирование делают вопросы сепсиса и септического шока предметом многочисленных исследований докторов различных специализаций.

Согласно данным III Международного консенсуса по определению сепсиса, это «угрожающая жизни органная дисфункция, вызванная дисрегуляцией ответа организма хозяина на инфекцию». Септический шок по определению М. Singer с соавт. - это клинический вариант сепсиса, при котором глубокие циркуляторные и клеточные/метаболические нарушения достаточны для значительного увеличения смертности или, согласно другому определению, это сепсис с персистирующей гипотензией, требующей вазопрессорной терапии для поддержания уровня АД $\geq 65$ мм рт. ст., а также уровня лактата $\geq 2$ ммоль/л при адекватной инфузионной терапии, что в целом повышает риск летального исхода [6].

Таким образом, можно утверждать, что сила, с которой организм хозяина ответит на инфекцию, зависит от множества фракторов, таких как пол, возраст, расовая принадлежность, коморбидность, а также осуществленные медицинские вмешательства, выступающие в роли стрессового фактора. Ответная реакция в общем виде представляет собой значительный выброс цитокинов, таких как IL-8, TNF- $\alpha$, а также гистамина. Полагается, что «сбой» именно на данном этапе и выступает в качестве пускового механизма в развитии сепсиса. Высвобождение крупного пула цитокинов приводит к повреждению эндотелия сосудов с повышением его проницаемости за счет адгезии нейтрофилов с последующим развитием нарушения микроциркуляции и отека. Кроме того, из поврежденных эндотелиоцитов в значительном количестве выделяется оксид азота, что ведет сначала к вазодилатации и гипотонии, а затем и к вазоплегии. В условиях децентрализации кровотока развивается гипоксия и ишемия тканей и органов, накопление активных форм кислорода и последующее за этим перекисное окисление липидов, что в свою очередь активирует систему комплемента по лектиновому пути. Компоненты комплемента С3а и С5а, образующиеся в ходе каскада реакций, выступают мощными хемоаттрактантами для иммунных клеток, готовых к выбросу цитокинов. Круг замыкается.

Сложна микробиология сепсиса и септического шока. Значительное количество микроорганизмов способны вызвать данные патологические состояния, кроме того, для каждой специализации характерны свои ведущие возбудители. Так как в 30 \% случаев установить возбудителя так и не удается, настойчиво рекомендуется начинать эмпирическую терапию антибиотиками широкого спектра действия до обнаружения конкретного возбудителя, чем скорее, тем лучше, в идеале - в течение 1 часа после установки диагноза, особенно у беременных с подозрением на сепсис, с последующей корректировкой препаратов.

Серьезные нарушения в системе гемостаза сопровождают септические процессы. Связь их рассматривается с позиции «петли усиления» - воспаление запускает и поддерживает процессы коагуляции, а продукты коагуляции поддерживают и усиливают воспаление. Больные с сепсисом должны рассматри- 
ваться как пациенты с протромботическим статусом со всеми возможными вытекающими из него осложнениями. Поэтому в случае, когда пациент изначально подвержен большему риску тромбообразования, например, при врожденных или приобретенных тромбофилиях, внимание врачей должно быть сосредоточено на коррекции показателей коагуляции.

у пациентов с септическими осложнениями возможно развитие ТТП с последующим формированием микроваскулярной обструкции с повреждением органов, в значительной степени головного мозга и почек, а также тромбоцитопении и неимунной гемолитической анемии [44]. Пациенты с сепсисом склонны к снижению уровня ADAMTS-13 менее $50 \%$ от нормального значения, а около $15 \%$ пациентов менее $10 \%$ от нормы. Чем ниже уровень ADAMTS-13, тем выше риск летального исхода у пациентов с сепси- сом и септическим шоком в связи с усугублением выраженности протромботического статуса. Не только дефицит ADAMTS-13 ведет к накоплению высоко активных мультимеров VWF, их количество значительно повышается за счет реакции эндотелиоцитов на системное воспаление в организме (примерно в 11 раз по сравнению с контрольной группой).

В заключение необходимо отметить, что вопросы сепсиса и септического шока сегодня находятся под пристальным вниманием медицинского сообщества. Основными целями являются снижение летальности, частоты и тяжести осложнений, модификация тех факторов риска, которые поддаются коррекции, а также поиск наиболее эфффективных и оптимальных алгоритмов терапии пациентов с септическими осложнениями.

\begin{tabular}{|c|c|}
\hline ИНФОРМАЦИЯ О СТАТЬЕ & ARTICLE INFORMATION \\
\hline Поступила: 13.05.2020. В доработанном виде: 10.07.2020. & Received: 13.05 .2020 . Revision received: 10.07 .2020 . \\
\hline Принята к печати: 16.07.2020. Опубликована онлайн: 17.07.2020. & Accepted: 16.07.2020. Published online: 17.07.2020. \\
\hline Вклад авторов & Author's contribution \\
\hline Все авторы сделали эквивалентный вклад в подготовку публикации. & Authors contributed equally to this article. \\
\hline Все авторы прочитали и утвердили окончательный вариант рукописи. & All authors have read and approved the final version of the manuscript. \\
\hline Конфликт интересов & Conflict of interests \\
\hline Авторы заявляют об отсутствии консрликта интересов. & The authors declare no conflict of interest. \\
\hline Финансирование & Funding \\
\hline $\begin{array}{l}\text { Авторы заявляют об отсутствии необходимости раскрытия финнансо- } \\
\text { вой поддержки. }\end{array}$ & The authors declare they have nothing to disclose regarding the funding \\
\hline Происхождение статьи и рецензирование & Provenance and peer review \\
\hline Журнал не заказывал статью; внешнее рецензирование. & Not commissioned; externally peer reviewed. \\
\hline
\end{tabular}

\section{Литература:}

1. Макацария А. Д., Акиньшина С. В., Бицадзе В.О. и др. Септический шок в акушерстве: новый взгляд на патогенез. Практическая медицина. 2012;(9):11-23.

2. Kumar G., Kumar N., Taneja A. et al. Nationwide trends of severe sepsis in the 21st century (2000-2007). Chest. 2011;140(5):1223-31. https://doi.org/10.1378/chest.11-0352.

3. Acosta C.D., Knight M., Lee H.C. et al. The continuum of maternal sepsis severity: incidence and risk factors in a population-based cohort study. PloS One. 2013;8(7):e67175. https://doi.org/10.1371/journal.pone.0067175.

4. Nelson J.E., Angus D. C., Weissfeld L. A. et al; Critical Care Peer Workgroup of the Promoting Excellence in End-of-Life Care Project. End-of-life care for the critically ill: A national intensive care unit survey. Crit Care Med. 2006;34(10);2547-53. https://doi.org/10.1097/01.CCM.0000239233.63425.1D.

5. Черешнев В.А., Гусев Е. Ю. Иммунологические и патофизиологические механизмы системного воспаления. Медицинская иммунология. 2012;14(1-2):9-20.

6. Seymour C. W., Liu V. X., Iwashyna T. J. et al. Assessment of clinical criteria for sepsis: for the Third International Consensus Definitions for Sepsis and Septic Shock (Sepsis-3). JAMA. 2016;315(8):762-74. https://doi.org/10.1001/jama.2016.0288.

7. Peigne V., Azoulay E., Coquet I. et al. The prognostic value of ADAMTS-13 (a disintegrin and metalloprotease with thrombospondin type 1 repeats, member 13) deficiency in septic shock patients involves interleukin- 6 and is not dependent on disseminated intravascular coagulation. Crit Care. 2013;17(6):R273. https://doi.org/10.1186/cc13115.
8. Shah B. A., Padbury J. F. Neonatal sepsis. An old problem with new insights. Virulence. 2014;5(1):170-8. https://doi.org/10.4161/viru.26906.

9. Al-Ostad G., Kezouh A., Spence A. R., Abenhaim H. A. Incidence and risk factors of sepsis mortality in labor, delivery and after birth: population-based study in the USA. J Obstet Gynaecol Res. 2015;41(8):1201-6. https://doi.org/10.1111/jog.12710.

10. Bauer M. E., Bateman B. T., Bauer S. T. et al. Maternal sepsis mortality and morbidity during hospitalization for delivery: temporal trends and independent associations for severe sepsis. Anesth Analg. 2013;17(4):944-50. https://doi.org/10.1213/ANE.0b013e3182a009c3.

11. Руднов В.А., Кулабухов В.В. Сепсис-3: обновленные ключевые положения, потенциальные проблемы и дальнейшие практические шаги. Вестник анестезиологии и реаниматологии. 2016;13(4):4-11.

12. Casserly B., Phillips G. S., Schorr C. et al. Lactate measurements in sepsis - induced tissue hypoperfusion: results from the Surviving Sepsis Campaign database. Crit Care Med. 2015;43(3):567-73. https://doi.org/10.1097/CCM.0000000000000742.

13. Продеус А. П., Устинова М. В., Корсунский А. А., Гончаров А.Г. Новые аспекты патогенеза сепсиса и септического шока у детей. Система комплемента как мишень для эффективной терапии. Инфекция и иммунитет. 2018;8(1):19-24. https://doi.org/10.15789/2220-7619-2018-1-19-24.

14. Plante L. A., Pacheco L. D., Louis J. M. SMFM Consult Series \#47: Sepsis during pregnancy and the puerperium. Am J Obstet Gynecol. 2019;220(4):B2-B10. https://doi.org/10.1016/j.ajog.2019.01.216.

15. Acosta C.D., Kurinczuk J. J., Lucas D. N. et al. Severe maternal sepsis in the UK, 2011-2012: a national case-control study. PLoS Med. 2014;11(7):e1001672. https://doi.org/10.1371/journal.pmed.1001672. 
16. Kramer H.M., Schutte J. M., Zwart J.J. et al. Maternal mortality and severe morbidity from sepsis in the Netherlands. Acta Obstet Gynecol Scand. 2009;88(6):647-53. https://doi.org/10.1080/00016340902926734.

17. Timezguid N., Das V., Hamdi A. et al. Maternal sepsis during pregnancy or the postpartum period requiring intensive care admission. Int J Obstet Anesth. 2012;21(1):51-5. https://doi.org/10.1016/j.ijoa.2011.10.009.

18. Drew R. J., Fonseca-Kelly Z., Eogan M. A retrospective audit of clinically significant maternal bacteraemia in a specialist maternity hospital from 2001 to 2014. Infect Dis Obstet Gynecol. 2015;2015:518562. https://doi.org/10.1155/2015/518562.

19. Bauer M. E., Lorenz R. P., Bauer S. T. et al. Maternal deaths due to sepsis in the state of Michigan, 1999-2006. Obstet Gynecol. 2015;126(4):747-52. https://doi.org/10.1097/AOG.0000000000001028.

20. Щеголев А. И., Мишнев О. Д., Туманова У.Н., Шувалова М. П. Неонатальный сепсис как причина перинатальной смертности в Российской Федерации. Международный журнал прикладных и фундаментальных исследований. 2016;(5-4):589-94.

21. Александрович Ю. С., Боронина И. В., Пшениснов К. В., Попова И. Н. Концентрация прокальцитонина как критерий отмены антибактериальной терапии при подозрении на ранний неонатальный сепсис у поздних недоношенных и доношенных новорожденных. Неонаталогия: новости, мнения, обучение. 2019;7(1):44-52 https://doi.org/10.24411/23082402-2019-11006.

22. Angus D. C., van der Poll T. Severe sepsis and septic shock. N Engl J Med. 2013;369(9):840-51. https://doi.org/10.1056/NEJMra1208623.

23. Hornik C.P., Benjamin D. K., Becker K. C. et al. Use of the complete blood cell count in early-onset neonatal sepsis. Pediatr Infect Dis J. 2012;31(8):799-802. https://doi.org/10.1097/INF.0b013e318256905c.

24. Connel T. G., Rele M., Cowley D. et al. How reliable as a negative blood culture result? Volume of blood submitted for culture in routine practice in a children's hospital. Pediatrics. 2007;119(5):891-6. https://doi.org/10.1542/peds.2006-0440.

25. Ди Ренцо Д. К., Макацария А. Д., Цибизова В. И. и др. 0 принципах работы перинатального стационара в условиях пандемии коронавируса. Вестник РАМН. 2020;75(1):83-92. https://doi.org/10.15690/vramn1324

26. Макацария А. Д., Григорьева К.Н., Мингалимов М. А. и др. Коронавирусная инфекция (COVID-19) и синдром диссеминированного внутрисосудистого свертывания. Акушерство, Гинекология и Репродукция. 2020;14(2):123-31. https://doi.org/10.17749/2313-7347.132.

27. Хизроева Д.Х., Макацария А. Д., Бицадзе В. О. и др. Лабораторный мониторинг COVID-19 и значение определения маркеров коагулопатии. Акушерство, Гинекология и Репродукция. 2020;14(2):132147. https://doi.org/10.17749/2313-7347.141.

28. Бицадзе В. О., Хизроева Д.Х., Макацария А. Д. и др. COVID-19, септический шок и синдром диссеминированного внутрисосудистого свертывания крови. Часть 1. Вестник РАМН. 2020;75(2):11828. https://doi.org/10.15690/vramn1335.

29. Бицадзе В. О., Хизроева Д. Х., Макацария А. Д. и др. COVID-19, септический шок и синдром диссеминированного внутрисосудистого свертывания крови. Часть 2. Вестник РАМН. 2020;75(2). [Принято к печати]. https://doi.org/10.15690/vramn1336.

30. Рогальская Е. А. Климович Л. Г., Самсонова Н. Н. Диагностика нарушений системы гемостаза при системном воспалении, сепсисе и полиорганной недостаточности в кардиохирургии. Бюллетень НЦССХ имени А. Н. Бакулева РАМН. Сердечно-сосудистые заболевания. 2016;17(S3):96

31. Semeraro N., Colucci M. Inflammation and thrombosis. In: Thrombosis fundamental and clinical aspects. Eds. J. Arnout, G. de Gaetano, M. Hoylaerts et al. Leuven: Leuven University Press, 2003. 433-59.

32. Мальцева Л. А., Базиленко Д. В. Патогенез тяжелого сепсиса и септического шока: анализ современных концепций. Медицина неотложных состояний. 2015;(7):35-40.

33. Levi M., Schultz M., van der Poll T. Sepsis and thrombosis. Semin Thromb Haemost. 2013;39(5):559-66. https://doi.org/10.1055/s-0033-1343894.

34. Stief T. W., ljagha 0., Weiste B. et al. Analysis of hemostasis alterations in sepsis. Blood Coagul Fibrinolysis. 2007;18(2):179-86. https://doi.org/10.1097/MBC.0b013e328040bf9a.

35. Asakura H., Ontachi Y., Mizutani T. et al. Depressed plasma activity of plasminogen or alpha2 plasmin inhibitor is not due to consumption coagulopathy in septic patients with disseminated intravascular coagulation. Blood Coagul Fibrinolysis. 2001;12(4):275-81. https://doi.org/10.1097/00001721-200106000-00008.

36. Dempfle C.E. The TAFI system. The new role of fibrinolysis. Hamostaseologie. 2007;27(4):278-81.

37. Gando S. Role of fibrinolysis in sepsis. Semin Thromb Haemost. 2013;39(4):392-9. https://doi.org/10.1055/s-0033-1334140.

38. Лопатин А. Ф., Редкин И. В., Самойленко В. В. и др. Роль антитромбина в диагностике и лечении сепсиса. Анестезиология и реаниматология. 2018;(3):19-24. https://doi.org/10.17116/anaesthesiology201803119.

39. Воробьева Н. А. Роль антитромбина в диагностике и интенсивной терапии острого ДВС-синдрома. Атеротромбоз. 2017;(2):53-69. https://doi.org/10.21518/2307-1109-2017-2-53-69.

40. Нехаев И. В., Приходченко А. О., Мазурина О.Г. и др. Полиорганная недостаточность, ССВР, ДВС-синдром и антитромбин III. Инфеекции в хирургии. 2015;13(1):17-26.

41. Opal S. M., van der Poll T. Endothelial barrier dysfunction in septic shock. J Intern Med. 2014;277(3):277-93. https://doi.org/10.1111/joim.12331.

42. Вавилова Т. В. Лабораторные исследования в диагностике синдрома ДВС. Новости хирургии. 2010;18(5):166-74.

43. Акиньшина С. В., Бицадзе В. О., Гадаева 3.К., Макацария А. Д. Значение тромботической микроангиопатии в патогенезе акушерских осложнений. Акушерство, Гинекология и Репродукция. 2015;9(2):62-71. https://doi.org/10.17749/2070-4968.2015.9.2.062-71.

44. Levi M., Scully M, Singer M. The role of ADAMTS-13 in the coagulopathy of sepsis. J Thromb Haemost. 2018;16(4):646-51. https://doi.org/10.1111/ith.13953.

45. Levi M., Opal S. Coagulation abnormalities in critically ill patients. Crit Care. 2006:10(4):222. https://doi.org/10.1186/cc4975

46. Schwameis M., Schorgenhofer C., Assinger A. et al. VWF excess and ADAMTS-13 deficiency: a unifying pathomechanism linking inflammation to thrombosis in DIC, malaria, and TTP. Thromb Haemost. 2015;113(4):708-18. https://doi.org/10.1160/TH14-09-0731.

47. McGill S.N., Ahmed N. A., Christou N. V. Increased plasma von Willebrand factor in the systemic inflammatory response syndrome is derived from generalized endothelial cell activation. Crit Care Med. 1998;26(2):296300. https://doi.org/10.1097/00003246-199802000-00031.

48. Bockmeyer C. L., Claus R. A., Budde U. et al. Inflammation-associated ADAMTS-13 deficiency promotes formation of ultra-large von Willebrand factor. Haematologica. 2008;93():137-40. https://doi.org/10.3324/haematol.11677.

49. Turner N. A., Moake J. Assembly and activation of alternative complement components on endothelial cell-anchored ultra-large von Willebrand factor links complement and hemostasis-thrombosis. PLOS ONE. 2013;8(3):e59372. https://doi.org/10.1371/journal.pone.0059372.

50. Ono T., Mimuro J., Madoiwa S. et al. Severe secondary deficiency of von Willebrand factor-cleaving protease (ADAMTS-13) in patients with sepsis-induced disseminated intravascular coagulation: its correlation with development of renal failure. Blood. 2006;107(2):528-34. https://doi.org/10.1182/blood-2005-03-1087.

51. Habe K., Wada H., Ito-Habe N. et al. Plasma ADAMTS-13, von Willebrand factor (VWF) and VWF propeptide profiles in patients with DIC and related diseases. Thromb Res. 2012;129(5):598-602. https://doi.org/10.1016/j.thromres.2011.10.011.

52. Sonneveld M., Franco O. H., Afran Ikram M. et al. Von Willebrand factor, ADAMTS-13, and the risk of mortality. Arterioscler Thromb Vasc Biol. 2016;36(12):2446-51. https://doi.org/10.1161/ATVBAHA.116.308225.

53. Emmer B. T., Ginsburg D., Desch K. C. Von Willebrand factor and ADAMTS-13. Too much or too little of a good thing? Arterioscler Thromb Vasc Biol. 2016;36(12):2281-2. https://doi.org/10.1161/ATVBAHA.116.308531.

54. George J., Nester C., McIntosh J. Syndromes of thrombotic microangiopathy associated with pregnancy. Hematology Am Soc Hematol Educ Program. 2015;2015:644-8. https://doi.org/10.1182/asheducation-2015.1.644.

55. Griffin P. T., Jaglal M. Metastatic prostate cancer mimicking thrombotic thrombocytopenic purpura. Blood. 2015;125(8):1349 https://doi.org/10.1182/blood-2014-11-608828.

56. Bobbio-Pallavicini E., Gugliotta L., Centurioni R. et al. Antiplatelet agents in thrombotic thrombocytopenic purpura (TTP): results 
of a randomized multicenter trial by the Italian cooperative group for TTP. Hematologia. 1997;82(4):429-35.

57. Medina P. J., Sipols J. M., George J. N. Drug-associated thrombotic thrombocytopenic purpura-hemolytic uremic syndrome. Curr Opin Hematol. 2001;8(5):286-93 https://doi.org/10.1097/00062752-200109000-00004

58. Reese J.A., Bougie D.W., Curtis B. R. et al. Drug-induced thrombotic microangiopathy: Experience of the Oklahoma Registry and the Blood Center of Wisconsin. Am J Hematol. 2015;90(5):406-10. https://doi.org/10.1002/ajh.23960.

59. Al-Nouri Z.L., Reese J.A., Terrell D. R. et al. Drug-induced thrombotic microangiopathy: a systematic review of published reports. Blood. 2015;125(4):616-8. https://doi.org/10.1182/blood-2014-11-611335.

\section{References:}

1. Makatsariya A. D., Akinshina S. V., Bitsadze V. O. et al. Septic shock in obstetrics: a new look at the pathogenesis. [Septicheskij shok v akusherstve: novyj vzglyad na patogenez]. Prakticheskaya medicina. 2012;(9):11-23. (In Russ.).

2. Kumar G., Kumar N., Taneja A. et al. Nationwide trends of severe sepsis in the 21st century (2000-2007). Chest. 2011;140(5):1223-31. https://doi.org/10.1378/chest.11-0352.

3. Acosta C.D., Knight M., Lee H. C. et al. The continuum of maternal sepsis severity: incidence and risk factors in a population-based cohort study. PloS One. 2013;8(7):e67175. https://doi.org/10.1371/journal.pone.0067175.

4. Nelson J.E., Angus D. C., Weissfeld L. A. et al; Critical Care Peer Workgroup of the Promoting Excellence in End-of-Life Care Project. End-of-life care for the critically ill: A national intensive care unit survey. Crit Care Med. 2006;34(10);2547-53. https://doi.org/10.1097/01.CCM.0000239233.63425.1D.

5. Chereshnev V.A., Gusev E. Yu. Immunological and pathophysiological mechanisms of systemic inflammation. [Immunologicheskie i patofiziologicheskie mekhanizmy sistemnogo vospaleniya]. Medicinskaya immunologiya. 2012;14(1-2):9-20. (In Russ.)

6. Seymour C. W., Liu V. X., Iwashyna T. J. et al. Assessment of clinical criteria for sepsis: for the Third International Consensus Definitions for Sepsis and Septic Shock (Sepsis-3). JAMA. 2016;315(8):762-74. https://doi.org/10.1001/jama.2016.0288.

7. Peigne V., Azoulay E., Coquet I. et al. The prognostic value of ADAMTS-13 (a disintegrin and metalloprotease with thrombospondin type 1 repeats, member 13) deficiency in septic shock patients involves interleukin- 6 and is not dependent on disseminated intravascular coagulation. Crit Care. 2013;17(6):R273. https://doi.org/10.1186/cc13115.

8. Shah B. A., Padbury J. F. Neonatal sepsis. An old problem with new insights. Virulence. 2014;5(1):170-8. https://doi.org/10.4161/viru.26906.

9. Al-Ostad G., Kezouh A., Spence A. R., Abenhaim H. A. Incidence and risk factors of sepsis mortality in labor, delivery and after birth: population-based study in the USA. J Obstet Gynaecol Res. 2015;41(8):1201-6. https://doi.org/10.1111/jog.12710.

10. Bauer M.E., Bateman B. T., Bauer S. T. et al. Maternal sepsis mortality and morbidity during hospitalization for delivery: temporal trends and independent associations for severe sepsis. Anesth Analg 2013;17(4):944-50. https://doi.org/10.1213/ANE.0b013e3182a009c3.

11. Rudnov V.A., Kulabukhov V. V. Sepsis 3: updated key positions, potential problems and further practical steps. [Sepsis-3: obnovlennye klyuchevye polozheniya, potencial'nye problemy i dal'nejshie prakticheskie shagi]. Vestnik anesteziologii i reanimatologii. 2016;13(4):4-11. (In Russ.).

12. Casserly B., Phillips G. S., Schorr C. et al. Lactate measurements in sepsis - induced tissue hypoperfusion: results from the Surviving Sepsis Campaign database. Crit Care Med. 2015;43(3):567-73. https://doi.org/10.1097/CCM.0000000000000742.

13. Prodeus A.P., Ustinova M. V., Korsunskiy A. A., Goncharov A. G. New aspects of sepsis and septic shock pathogenesis in children. The complement system as target for an effective therapy. [Novye aspekty patogeneza sepsisa i septicheskogo shoka u detej. Sistema komplementa kak mishen' dlya effektivnoj terapii]
60. Макацария А.Д., Бицадзе В. О., Хизроева Д. Х. Катастрофический антифосфолипидный синдром и тромботический «шторм». Сибирский медицинский журнал. 2010;25(4):118-23.

61. Asherson R. A. Multiorgan failure and antiphospholipid antibodies: the catastrophic antiphospholipid (Asherson's) syndrome. Immunobiology. 2005;210(10):727-33. https://doi.org/10.1016/j.imbio.2005.10.002.

62. Bucciarelli S., Espinosa G., Cervera R. et al. Mortality in the catastrophic antiphospholipid syndrome: Causes of death and prognostic factors in a series of 250 patients. Arthritis Rheum. 2006;54(8):2568-76. https://doi.org/10.1002/art.22018.

63. Asherson R. A. The catastrophic antiphospholipid (Asherson's) syndrome. Autoimm Rev. 2006;6(2):65-7. https://doi.org/10.1016/j.autrev.2006.06.012.

Infekciya i immunitet. 2018;8(1):19-24. (In Russ.) https://doi.org/10.15789/2220-7619-2018-1-19-24.

14. Plante L. A., Pacheco L. D., Louis J. M. SMFM Consult Series \#47: Sepsis during pregnancy and the puerperium. Am J Obstet Gynecol. 2019;220(4):B2-B10. https://doi.org/10.1016/j.ajog.2019.01.216.

15. Acosta C.D., Kurinczuk J. J., Lucas D. N. et al. Severe maternal sepsis in the UK, 2011-2012: a national case-control study. PLoS Med. 2014;11(7):e1001672. https://doi.org/10.1371/journal.pmed.1001672.

16. Kramer H. M., Schutte J. M., Zwart J. J. et al. Maternal mortality and severe morbidity from sepsis in the Netherlands. Acta Obstet Gynecol Scand. 2009;88(6):647-53. https://doi.org/10.1080/00016340902926734.

17. Timezguid N., Das V., Hamdi A. et al. Maternal sepsis during pregnancy or the postpartum period requiring intensive care admission. Int J Obstet Anesth. 2012;21(1):51-5. https://doi.org/10.1016/j.ijoa.2011.10.009.

18. Drew R. J., Fonseca-Kelly Z., Eogan M. A retrospective audit of clinically significant maternal bacteraemia in a specialist maternity hospital from 2001 to 2014. Infect Dis Obstet Gynecol. 2015;2015:518562. https://doi.org/10.1155/2015/518562.

19. Bauer M. E., Lorenz R. P., Bauer S. T. et al. Maternal deaths due to sepsis in the state of Michigan, 1999-2006. Obstet Gynecol. 2015;126(4):747-52. https://doi.org/10.1097/AOG.0000000000001028.

20. Shchegolev A. I., Mishnev O.D., Tumanova U. N., Shuvalova M.P. Neonatal sepsis as a cause of perinatal mortality in the Russian Federation. [Neonatal'nyj sepsis kak prichina perinatal'noj smertnosti v Rossijskoj Federacii]. Mezhdunarodnyj zhurnal prikladnyh $i$ fundamental'nyh issledovanij. 2016;(5-4):589-94. (In Russ.).

21. Aleksandrovich Yu.S., Boronina I. V., Pshenisnov K. V., Popova I. N Concentration of serum procalcitonin as a criterion of antibacterial therapy refuse in groups of late prematerm and term newborns with suspected early neonatal sepsis. [Koncentraciya prokal'citonina kak kriterij otmeny antibakterial'noj terapii pri podozrenii na rannij neonatal'nyj sepsis u pozdnih nedonoshennyh i donoshennyh novorozhdennyh]. Neonatalogiya: novosti, mneniya, obuchenie. 2019;7(1):44-52. (In Russ.). https://doi.org/10.24411/23082402-2019-11006.

22. Angus D. C., van der Poll T. Severe sepsis and septic shock. N Eng/ J Med. 2013;369(9):840-51. https://doi.org/10.1056/NEJMra1208623.

23. Hornik C.P., Benjamin D.K., Becker K. C. et al. Use of the complete blood cell count in early-onset neonatal sepsis. Pediatr Infect Dis J. 2012;31(8):799-802. https://doi.org/10.1097/INF.0b013e318256905c.

24. Connel T.G., Rele M., Cowley D. et al. How reliable as a negative blood culture result? Volume of blood submitted for culture in routine practice in a children's hospital. Pediatrics. 2007;119(5):891-6. https://doi.org/10.1542/peds.2006-0440.

25. Di Renzo G. K., Makatsariya A. D., Tsibizova V. I. et al. Obstetric and perinatal care units functioning during the COVID-19 pandemic. [0 principah raboty perinatal'nogo stacionara $v$ usloviyah pandemii koronavirusa]. Vestnik RAMN. 2020;75(1):83-92. (In Russ.). https://doi.org/10.15690/vramn1324

26. Makatsariya A.D., Grigorieva K. N., Mingalimov M.A. et al. Coronavirus disease (COVID-19) and disseminated intravascular coagulation. [Koronavirusnaya infekciya (COVID-19) i sindrom disseminirovannogo vnutrisosudistogo svertyvaniya]. Akusherstvo, Ginekologia i Reprodukcia. 2020;14(2):123-31. (In Russ.) https://doi.org/10.17749/2313-7347.132 
27. Khizroeva J. Kh., Makatsariya A. D., Bitsadze V. O. et al. Laboratory monitoring of COVID-19 patients and importance of coagulopathy markers. [Laboratornyj monitoring COVID-19 znachenie opredeleniya markerov koagulopatii]. Akusherstvo, Ginekologia i Reprodukcia. 2020;14(2):132-147. (In Russ.). https://doi.org/10.17749/2313-7347.141.

28. Bitsadze V. O., Khizroeva J. Kh., Makatsariya A. D. et al. COVID-19, septic shock and syndrome of disseminated intravascular coagulation. Part 1. [COVID-19, septicheskij shok i sindrom disseminirovannogo vnutrisosudistogo svertyvaniya krovi. Chast' 1]. Vestnik RAMN. 2020;75(2):118-28. (In Russ.). https://doi.org/10.15690/vramn1335

29. Bitsadze V. 0., Khizroeva J. Kh., Makatsariya A. D. et al. COVID-19, septic shock and syndrome of disseminated intravascular coagulation. Part 2. [COVID-19, septicheskij shok i sindrom disseminirovannogo vnutrisosudistogo svertyvaniya krovi. Chast' 2]. Vestnik RAMN. 2020;75(2). [Article in press]. (In Russ.). https://doi.org/10.15690/vramn1336.

30. Rogalskaya E. A. Klimovich L. G., Samsonova N. N. Diagnostics of hemostasis disturbances in systemic inflammation, sepsis and multiple organ failure in cardiac surgery. [Diagnostika narushenij sistemy gemostaza pri sistemnom vospalenii, sepsise i poliorgannoj nedostatochnosti v kardiohirurgii]. Byulleten' NCSSH imeni A.N. Bakuleva RAMN. Serdechno-sosudistye zabolevaniya. 2016;17(S3):96. (In Russ.).

31. Semeraro N., Colucci M. Inflammation and thrombosis. In: Thrombosis fundamental and clinical aspects. Eds. J. Arnout, G. de Gaetano, M. Hoylaerts et al. Leuven: Leuven University Press, 2003. 433-59.

32. Maltseva L. A., Bazilenko D.V. The pathogenesis of severe sepsis and septic shock: analysis of modern concepts. [Patogenez tyazhelogo sepsisa i septicheskogo shoka: analiz sovremennyh koncepcij]. Medicina neotlozhnyh sostoyanij. 2015;(7):35-40. (In Russ.).

33. Levi M., Schultz M., van der Poll T. Sepsis and thrombosis. Semin Thromb Haemost. 2013;39(5):559-66. https://doi.org/10.1055/s-0033-1343894.

34. Stief T.W., ljagha 0., Weiste B. et al. Analysis of hemostasis alterations in sepsis. Blood Coagul Fibrinolysis. 2007;18(2):179-86. https://doi.org/10.1097/MBC.0b013e328040bf9a.

35. Asakura H., Ontachi Y., Mizutani T. et al. Depressed plasma activity of plasminogen or alpha2 plasmin inhibitor is not due to consumption coagulopathy in septic patients with disseminated intravascular coagulation. Blood Coagul Fibrinolysis. 2001;12(4):275-81. https://doi.org/10.1097/00001721-200106000-00008.

36. Dempfle C.E. The TAFI system. The new role of fibrinolysis. Hamostaseologie. 2007;27(4):278-81.

37. Gando S. Role of fibrinolysis in sepsis. Semin Thromb Haemost. 2013;39(4):392-9. https://doi.org/10.1055/s-0033-1334140.

38. Lopatin A. F., Redkin I. V., Samoylenko V.V. et al. The role of antithrombin in the diagnosis and treatment of sepsis. [Rol' antitrombina v diagnostike i lechenii sepsisa]. Anesteziologiya $i$ reanimatologiya. 2018;(3):19-24. (In Russ.). https://doi.org/10.17116/anaesthesiology201803119.

39. Vorobieva N. A. Role of antithrombin in diagnosis and intensive therapy of acute DIC-syndrome (review of literature and evidence of actual clinical practice). [Rol' antitrombina v diagnostike i intensivnoj terapii ostrogo DVS-sindroma]. Aterotromboz. 2017;(2):53-69. (In Russ.) https://doi.org/10.21518/2307-1109-2017-2-53-69.

40. Nekhaev I.V., Prikhodchenko A. O., Mazurina 0. G. and others. Multiple organ failure, SIRS, thrombohemorrhagic syndrome and antithrombin III. [Poliorgannaya nedostatochnost', SSVR, DVS-sindrom i antitrombin III]. Infekcii v hirurgii. 2015;13(1):17-26. (In Russ.).

41. Opal S. M., van der Poll T. Endothelial barrier dysfunction in septic shock. J Intern Med. 2014;277(3):277-93. https://doi.org/10.1111/joim.12331.

42. Vavilova T.V. Laboratory tests in the diagnosis of DIC syndrome. [Laboratornye issledovaniya $v$ diagnostike sindroma DVS]. Novosti hirurgii. 2010;18(5):166-74. (In Russ.).

43. Akinshina S. V., Bitsadze V. O., Gadaeva Z. K., Makatsariya A. D. Thrombotic microangiopathy in the pathogenesis of obstetric complications. [Znachenie tromboticheskoj mikroangiopatii v patogeneze akusherskih oslozhnenij]. Akusherstvo, Ginekologia i Reprodukcia. 2015;9(1):62-71. (In Russ.). https://doi.org/10.17749/2070-4968.2015.9.2.062-71.
44. Levi M., Scully M, Singer M. The role of ADAMTS-13 in the coagulopathy of sepsis. J Thromb Haemost. 2018;16(4):646-51. https://doi.org/10.1111/jth.13953.

45. Levi M., Opal S. Coagulation abnormalities in critically ill patients. Crit Care. 2006;10(4):222. https://doi.org/10.1186/cc4975.

46. Schwameis M., Schorgenhofer C., Assinger A. et al. VWF excess and ADAMTS-13 deficiency: a unifying pathomechanism linking inflammation to thrombosis in DIC, malaria, and TTP. Thromb Haemost. 2015;113(4):708-18. https://doi.org/10.1160/TH14-09-0731.

47. McGill S.N., Ahmed N. A., Christou N. V. Increased plasma von Willebrand factor in the systemic inflammatory response syndrome is derived from generalized endothelial cell activation. Crit Care Med. 1998;26(2):296300. https://doi.org/10.1097/00003246-199802000-00031.

48. Bockmeyer C. L., Claus R. A., Budde U. et al. Inflammation-associated ADAMTS-13 deficiency promotes formation of ultra-large von Willebrand factor. Haematologica. 2008;93():137-40. https://doi.org/10.3324/haematol.11677.

49. Turner N. A., Moake J. Assembly and activation of alternative complement components on endothelial cell-anchored ultra-large von Willebrand factor links complement and hemostasis-thrombosis. PLOS ONE. 2013;8(3):e59372. https://doi.org/10.1371/journal.pone.0059372.

50. Ono T., Mimuro J., Madoiwa S. et al. Severe secondary deficiency of von Willebrand factor-cleaving protease (ADAMTS-13) in patients with sepsis-induced disseminated intravascular coagulation: its correlation with development of renal failure. Blood. 2006;107(2):528-34. https://doi.org/10.1182/blood-2005-03-1087.

51. Habe K., Wada H., Ito-Habe N. et al. Plasma ADAMTS-13, von Willebrand factor (VWF) and VWF propeptide profiles in patients with DIC and related diseases. Thromb Res. 2012;129(5):598-602. https://doi.org/10.1016/j.thromres.2011.10.011.

52. Sonneveld M., Franco O. H., Afran Ikram M. et al. Von Willebrand factor, ADAMTS-13, and the risk of mortality. Arterioscler Thromb Vasc Biol. 2016;36(12):2446-51. https://doi.org/10.1161/ATVBAHA.116.308225.

53. Emmer B.T., Ginsburg D., Desch K. C. Von Willebrand factor and ADAMTS-13. Too much or too little of a good thing? Arterioscler Thromb Vasc Biol. 2016;36(12):2281-2. https://doi.org/10.1161/ATVBAHA.116.308531.

54. George J., Nester C., McIntosh J. Syndromes of thrombotic microangiopathy associated with pregnancy. Hematology Am Soc Hematol Educ Program. 2015;2015:644-8. https://doi.org/10.1182/asheducation-2015.1.644.

55. Griffin P. T., Jaglal M. Metastatic prostate cancer mimicking thrombotic thrombocytopenic purpura. Blood. 2015;125(8):1349. https://doi.org/10.1182/blood-2014-11-608828.

56. Bobbio-Pallavicini E., Gugliotta L., Centurioni R. et al. Antiplatelet agents in thrombotic thrombocytopenic purpura (TTP): results of a randomized multicenter trial by the Italian cooperative group for TTP. Hematologia. 1997;82(4):429-35.

57. Medina P.J., Sipols J. M., George J. N. Drug-associated thrombotic thrombocytopenic purpura-hemolytic uremic syndrome. Curr Opin Hematol. 2001;8(5):286-93. https://doi.org/10.1097/00062752-200109000-00004.

58. Reese J.A., Bougie D.W., Curtis B. R. et al. Drug-induced thrombotic microangiopathy: Experience of the Oklahoma Registry and the Blood Center of Wisconsin. Am J Hematol. 2015;90(5):406-10. https://doi.org/10.1002/ajh.23960.

59. Al-Nouri Z.L., Reese J. A., Terrell D. R. et al. Drug-induced thrombotic microangiopathy: a systematic review of published reports. Blood. 2015;125(4):616-8. https://doi.org/10.1182/blood-2014-11-611335.

60. Makatsariya A. D., Bitsadze V. O., Khizroeva J. Kh. Catastrophic antiphospholipid syndrome and thrombotic storm. [Katastroficheskij antifosfolipidnyj sindrom i tromboticheskij «shtorm»]. Sibirskij medicinskij zhurnal. 2010;25(4):118-23. (In Russ.).

61. Asherson R. A. Multiorgan failure and antiphospholipid antibodies: the catastrophic antiphospholipid (Asherson's) syndrome. Immunobiology. 2005;210(10):727-33. https://doi.org/10.1016/j.imbio.2005.10.002.

62. Bucciarelli S., Espinosa G., Cervera R. et al. Mortality in the catastrophic antiphospholipid syndrome: Causes of death and prognostic factors in a series of 250 patients. Arthritis Rheum. 2006;54(8):2568-76. https://doi.org/10.1002/art.22018.

63. Asherson R.A. The catastrophic antiphospholipid (Asherson's) syndrome Autoimm Rev. 2006;6(2):65-7. https://doi.org/10.1016/.jautrev.2006.06.012. 


\section{Сведения об авторах:}

Бицадзе Виктория Омаровна - д.м.Н., профессор РАН, профессор кафедры акушерства и гинекологии Клинического института детского здоровья имени Н.Ф. Филатова ФГАОУ ВО Первый Московский государственный медицинский университет имени И. М. Сеченова (Сеченовский университет), Москва, Россия. ORCID: https://orcid.org/0000-0001-8404-1042. Scopus Author ID: 6506003478. Researcher ID: F-8409-2017.

Суконцева Татьяна Александровна - студент 6-го курса лечебного факультета ФГБОУ ВО «Первый Санкт-Петербургский государственный медицинский университет имени академика И. П. Павлова» Министерства здравоохранения Российской Федерации, Санкт-Петербург, Россия. ORCID: https://orcid.org/0000-0002-6907-6746.

Акиньшина Светлана Владимировна - к.м.н., научный сотрудник кафедры акушерства и гинекологии Клинического института детского здоровья имени Н.Ф. Филатова ФГАОУ ВО Первый Московский государственный медицинский университет имени И. М. Сеченова (Сеченовский университет), Москва, Россия. ORCID: https://orcid.org/0000-0001-6012-453X.

Сулина Яна Юрьевна - ассистент кафедры акушерства и гинекологии Клинического института детского здоровья имени Н. Ф. Филатова ФГАОУ ВО Первый Московский государственный медицинский университет имени И. М. Сеченова Министерства здравоохранения Российской Федерации (Сеченовский Университет), Москва, Россия. ORCID: https://orcid.org/0000-0001-7702-2687. Scopus Author ID: 57194140583. Researcher ID: S-9569-2018. Хизроева Джамиля Хизриевна - д.м.Н., профрессор кафедры акушерства и гинекологии Клинического института детского здоровья имени Н. Ф. Филатова ФГАОУ ВО Первый Московский государственный медицинский университет имени И. М. Сеченова (Сеченовский университет), Москва, Россия. ORCID: https://orcid.org/0000-0002-0725-9686. Scopus Author ID: 57194547147. Researcher ID: F-8384-2017.

Третьякова Мария Владимировна - к.м.н., врач акушер-гинеколог отделения гинекологии 000 «Лечебный Центр», Москва, Россия.

Султангаджиева Хадижат Гасановна - аспирант кафедры акушерства и гинекологии Клинического института детского здоровья имени Н. Ф. Филатова ФГАОУ ВО Первый Московский государственный медицинский университет имени И. М. Сеченова Министерства здравоохранения Российской Федерации (Сеченовский Университет), Москва, Россия. ORCID: https://orcid.org/0000-0001-6192-1936

Унгиадзе Джумбер Юрьевич - Д.м.н., профессор медицинского факультета, Батумский государственный университет имени Шота Руставели, Батуми, Грузия; директор Центра здоровья «Медина» имени Ирис Борчашвили», Батуми, Грузия. ORCID: https://orcid.org/0000-0002-3337-4995.

Самбурова Наталья Викторовна - к.м.н., доцент кафедры патофизиологии Института клинической медицины ФГАОУ ВО Первый Московский государственный медицинский университет имени И. М. Сеченова Министерства здравоохранения Российской Федерации (Сеченовский Университет), Москва, Россия. ORCID: https://orcid.org/0000-0002-4564-8439.

Григорьева Кристина Николаевна - студент 6-го курса педиатрического факультета ФГАОУ ВО Первый Московский государственный медицинский университет имени И.М. Сеченова Министерства здравоохранения Российской Федерации (Сеченовский университет), Москва, Россия. ORCID: https://orcid.org/0000-0002-7756-8935.

Цибизова Валентина Ивановна - врач отделения функциональной и ультразвуковой диагностики ФГБУ «Национальный медицинский исследовательский центр имени В.А. Алмазова» Министерства здравоохранения Российской Федерации, Санкт-Петербург, Россия. ORCID: https://orcid.org/0000-0001-5888-0774.

Шкода Андрей Сергеевич - д.м.н., профессор, главный врач ГБУЗ «Городская клиническая больница № 67 имени Л. А. Ворохобова Департамента здравоохранения города Москвы», Москва, Россия. ORCID: https://orcid.org/0000-0002-9783-1796.

Блинов Дмитрий Владиславович - к.м.н., руководитель по медицинским и научным вопросам, Институт Превентивной и Социальной Медицины, Москва, Россия; врач-невролог, Клинический Госпиталь Лапино, ГК «Мать и Дитя», Московская область, Россия; преподаватель, кафедра неврологии, психиатрии и наркологии, АНО ДПО «Московский медико-социальный институт им. Ф.П. Гааза», Москва, Россия. ORCID: https://orcid.org/0000-0002-3367-9844. Researcher ID: E-8906-2017. RSCl: 9779-8290.

Макацария Александр Давидович - д.м.Н., академик РАН, профессор, зав. кафедрой акушерства и гинекологии Клинического института детского здоровья имени Н.Ф. Филатова ФГАОУ ВО Первый Московский государственный медицинский университет имени И. М. Сеченова Министерства здравоохранения Российской Федерации (Сеченовский Университет), Москва, Россия. ORCID: https://orcid.org/0000-0001-7415-4633. Scopus Author ID: 6602363216. Researcher ID: M-5660-2016.

\section{About the authors:}

Viktoria O. Bitsadze - MD, Dr Sci Med, Professor of RAS, Professor, Department of Obstetrics and Gynecology, N. F. Filatov Clinical Institute of Children's Health, Sechenov University, Moscow, Russia. ORCID: https://orcid.org/0000-0001-8404-1042. Scopus Author ID: 6506003478. Researcher ID: F-8409-2017.

Sukontseva Tatyana Alexandrovna $-6^{\text {th }}$ year Student, Faculty of General Medicine, I.P. Pavlov First Saint Petersburg State Medical University, Saint Petersburg, Russia. ORCID: https://orcid.org/0000-0002-6907-6746.

Svetlana V. Akinshina - MD, PhD, Researcher, Department of Obstetrics and Gynecology, N. F. Filatov Clinical Institute of Children's Health, Sechenov University, Moscow, Russia. ORCID: https://orcid.org/0000-0001-6012-453X.

Yana Yu. Sulina - MD, Assistant, Department of Obstetrics and Gynecology, N. F. Filatov Clinical Institute of Children's Health, Sechenov University, Moscow, Russia. ORCID: https://orcid.org/0000-0001-7702-2687. Scopus Author ID: 57194140583. Researcher ID: S-9569-2018.

Jamilya Kh. Khizroeva - MD, Dr Sci Med, Professor, Department of Obstetrics and Gynecology, N. F. Filatov Clinical Institute of Children's Health, Sechenov University, Moscow, Russia. ORCID: https://orcid.org/0000-0002-0725-9686. Scopus Author ID: 57194547147. Researcher ID: F-8384-2017.

Maria V. Tretyakova - MD, PhD, Obstetrician-Gynecologist, Department of Gynecology, «Medical Center» LLC, Moscow, Russia.

Khadizhat G. Sultangadzhieva - Postgraduate Student, Department of Obstetrics and Gynecology, N. F. Filatov Clinical Institute of Children's Health, Sechenov University, Moscow, Russia. ORCID: https://orcid.org/0000-0001-6192-1936.

Jumber Yu. Ungiadze - MD, Dr Sci Med, Professor, Faculty of Medicine, Batumi Shota Rustaveli State University, Batumi, Georgia; Director of the Iris Borchashvili Health Center Medina, Batumi, Georgia. ORCID: https://orcid.org/0000-0002-3337-4995.

Natalia V. Samburova - PhD, Associate Professor, Department of Pathophysiology, Institute of Clinical Medicine, Sechenov University, Moscow, Russia. ORCID: https://orcid.org/0000-0002-4564-8439.

Kristina N. Grigoreva $-6^{\text {th }}$ year Student, Faculty of Pediatrics, Sechenov University, Moscow, Russia. ORCID: https://orcid.org/0000-0002-7756-8935.

Valentina I. Tsibizova - MD, Department of Functional and Ultrasound Diagnostics, Almazov National Medical Research Centre, Saint Petersburg, Russia. ORCID: https://orcid.org/0000-0001-5888-0774.

Andrey S. Shkoda - MD, Dr Sci Med, Professor, Chief Physician, City Clinical Hospital № 67 named after L. A. Vorokhobov, Moscow Healthcare Department, Moscow, Russia. ORCID: https://orcid.org/0000-0002-9783-1796.

Dmitry V. Blinov - MD, PhD, MBA, Head of Medical and Scientific Affairs, Institute of Preventive and Social Medicine, Moscow, Russia; Neurologist, Lapino Clinic Hospital, MD Medical Group, Moscow Region, Russia; Faculty Member, Department of Neurology, Psychiatry and Narcology, Moscow Haass Medical - Social Institute, Moscow, Russia. ORCID: https://orcid.org/0000-0002-3367-9844

Alexander D. Makatsariya - MD, Dr Sci Med, Professor, Academician of RAS, Head of the Department of Obstetrics and Gynecology, N. F. Filatov Clinical Institute of Children's Health, Sechenov University, Moscow, Russia. ORCID: https://orcid.org/0000-0001-7415-4633. Scopus Author ID: 6602363216. Researcher ID: M-5660-2016. 